\title{
Leaders
}

\section{Classification of acute leukaemia: the need to incorporate cytogenetic and molecular genetic information}

\author{
Barbara J Bain
}

The purpose of any classification of leukaemia is to identify distinct biological entities which differ in aetiology, mechanisms of leukaemogenesis, clinicopathological features, and prognosis. Since the optimal treatment for such entities differs, their recognition is not only of scientific interest but is also essential for optimal care of patients.

Acute leukaemia can be classified in many ways:

(1) by morphology and cytochemistry supplemented by immunophenotyping, as proposed by the French-American-British (FAB) group ${ }^{1}$;

(2) by morphology, immunophenotyping and cytogenetics as proposed by the MIC groups $^{2}$;

(3) by immunophenotyping alone, as proposed by the European Group for the Immunological Classification of Leukemias (EGIL) ${ }^{4}$;

(4) by antecedent events;

(5) by the nature of the stem cell or progenitor cell in which the leukaemogenic mutation occurred. ${ }^{5}$

In addition, it has recently been proposed that acute myeloid leukaemia (AML) should be classified either as myelodysplastic syndrome (MDS) related or as true de novo AML. ${ }^{6}$ Finally, consideration should be given to a classification of acute leukaemia which incorporates molecular genetic information.

In 1976 the FAB group ${ }^{1}$ published the first of an important series of papers concerning the classification of acute leukaemia. Initially classification was based on cytology and cytochemistry. Subsequently the development of immunophenotyping provided a firm basis for the diagnosis of acute lymphoblastic leukaemia and facilitated the diagnosis of acute megakaryoblastic leukaemia ${ }^{7}$ and acute myeloid leukaemia with minimal evidence of myeloid differentiation (M0 AML). ${ }^{8}$ Some morphological categories recognised by the FAB group, specifically acute hypergranular promyelocytic leukaemia and its variant form (M3 and M3 variant AML) and L3 acute lymphoblastic leukaemia (ALL), were subsequently shown to indeed be biological entities; application of the FAB criteria still permits their speedy diagnosis. Other FAB categories include several different discrete entities and some of these overlap several FAB groups. Despite this, the FAB classifications remain of great importance in providing a widely accepted terminology and a framework into which knowledge gained from newer techniques can be incorporated.

Following development of immunophenotyping techniques and the improvement of cytogenetic methods for haematological malig-

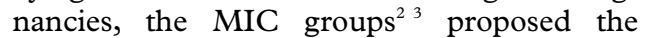
classification of acute leukaemia on the basis of the FAB morphological classification supplemented by immunophenotype and cytogenetics - a morphological, immunological, cytogenetic (MIC) classification. The MIC classifications defined the cytogenetic correlates of the FAB categories of M3 AML and L3 ALL. In addition, several new entities were recognised, for example subsets of $B$ lineage ALL associated with $\mathrm{t}(1 ; 19)(\mathrm{q} 23 ; \mathrm{p} 13)$, $\mathrm{t}(4 ; 11)(\mathrm{q} 21 ; \mathrm{q} 23)$, and $\mathrm{t}(9 ; 22)(\mathrm{q} 34 ; \mathrm{q} 11)$, and subsets of AML associated with $\mathrm{t}(8 ; 21)(\mathrm{q} 22 ; \mathrm{q} 22)$ and $\operatorname{inv}(16)(\mathrm{p} 13 \mathrm{q} 22)$. Most of the MIC categories continue to be recognised as discrete entities, although the validity of categories of ALL defined by the presence of deletion of the long arm of chromosome 6 [del(6q)] or deletion of the short arm of chromosome 9 [del(9p)] might be questioned. The MIC classifications are seen as open ended, with new categories being added once their characteristics have been clearly defined.

The European Group for the Immunological Classification of Leukemias (EGIL) ${ }^{4}$ has proposed that acute leukaemia be classified on the basis of immunophenotype alone. This classification has the strength that it suggests standardised criteria for defining a leukaemia as myeloid, $\mathrm{T}$ lineage, $\mathrm{B}$ lineage, or biphenotypic. It also suggests criteria for distinguishing biphenotypic leukaemia from AML with aberrant expression of lymphoid antigens, and from ALL with aberrant expression of myeloid antigens. However, a purely immunological classification has the disadvantage that discrete entities may fall into one of two categories; for example some cases of AML of FAB M2 subtype associated with $\mathrm{t}(8 ; 21)(\mathrm{q} 22 ; \mathrm{q} 22)$ would be classified as "AML of myelomonocytic lineage" while others would be classified as "AML 
Table 1 Classification of acute leukaemia by antecedent events

De novo

Following myelodysplastic syndromes

Following myeloproliferative disorders

Following paroxysmal nocturnal haemoglobinuria

Treatment related

Following alkylating agents

Following topoisomerase-II interactive drugs

Following congenital or acquired aplastic anaemia

with lymphoid antigen expression," depending on whether or not a case showed aberrant expression of CD19. In addition, rare cases of acute leukaemia have been described which were clearly myeloid when assessed by cytology and cytochemistry but which did not express any of the commonly investigated myeloid antigens.

Classification of acute leukaemia by antecedent events (table 1) is clearly relevant to prognosis and should be considered in classifying any case of acute leukaemia. This classification is of particular relevance to AML but is also applicable to ALL. Although most cases of ALL occur de novo, treatment related cases are recognised after exposure to topoisomerase-II interactive drugs, and secondary cases occur as an acute transformation not only during the course of chronic myeloid leukaemia but also probably on rare occasions during the course of other myeloproliferative disorders or myelodysplastic syndromes. It should be noted that the FAB classification was initially envisaged as applicable to de novo acute leukaemia and is less readily applicable to secondary leukaemia.

It has been proposed that acute leukaemia should be classified on the basis of the nature of the cell in which the leukaemogenic mutation occurred (pluripotent stem cell, multipotent stem cell, or committed stem cell). ${ }^{5}$ Although the cell of origin is likely to be of considerable biological importance, with a better prognosis usually being associated with a leukaemic clone originating further down the stem cell hierarchy, it has been difficult in practice to devise a workable scheme. Although in some cases the leukaemic clone clearly derives from a pluripotent haemopoietic-lymphoid stem cell it is not always possible to determine this reliably.

In relation to AML, it has recently been suggested that cases should be divided into two broad groups designated respectively "MDS related AML" and "true de novo AML." MDS related AML includes not only cases which have followed MDS but also (1) alkylating agent related AML, (2) AML following Fanconi's anaemia, (3) the majority of cases of AML in the elderly, and (4) a minority of cases in the young. In MDS related AML the leukaemic clone is derived from a multipotent (or pluripotent) stem cell. Trilineage dysplasia is common, prognosis is poor, and if remission occurs haemopoiesis may still be clonal. The category designated "true de novo AML" includes the majority of cases of AML in the young. There is neither preceding MDS nor trilineage myelodysplasia, polyclonal haemopoiesis is restored after remission, and prognosis is relatively good. This type of leukaemia may originate in a lineage restricted stem cell.
The characteristic cytogenetic abnormalities differ between the two groups. MDS related AML is associated with monosomy or deletion of the long arm of chromosome 5 or 7 , in association with a complex karyotype and with certain specific deletions, monosomies, trisomies, translocations, or inversions (for example, +8, del(11q), del(12p), -18, +19, $\operatorname{del}(20 \mathrm{q}), \quad+21, \quad \mathrm{t}(1 ; 7)(\mathrm{q} 10 ; \mathrm{p} 10), \quad \mathrm{t}(2 ; 11)$ (p21;q23) and inversions and translocations involving chromosome 3 bands q21 and q26). "True de novo AML" is associated predominantly with balanced translocations and inversions, for example, $\mathrm{t}(9 ; 11)(\mathrm{p} 22 ; \mathrm{q} 23)$, $\mathrm{t}(8 ; 21)(\mathrm{q} 22 ; \mathrm{q} 22), \mathrm{t}(11 ; 17)(\mathrm{q} 23 ; \mathrm{q} 21), \mathrm{t}(15 ; 17)$ (q22; q11-12), $\quad \operatorname{inv}(16)(\mathrm{p} 13 \mathrm{q} 22), \quad \mathrm{t}(16 ; 16)$ (p13;q22). Some details of this proposed classification may be questioned. Thus the allocation of cases with $t(6 ; 9)(\mathrm{p} 23 ; \mathrm{q} 34)$ to the second group may not be appropriate since they may evolve from MDS and are often associated with trilineage myelodysplasia. The designation "de novo type AML" might be preferable to "true de novo AML" since at least some cases of acute leukaemia following topoisomerase-II interactive drugs appears to fit into this category rather than into the category of MDS related AML. Nevertheless this proposed classification is potentially very useful.

Finally, consideration must be given to the value of formally incorporating molecular genetic information into the classification of acute leukaemia. Leukaemia can be viewed as an acquired genetic disorder, resulting from a somatic mutation. It is likely that it is the precise alteration in DNA which is the essential factor determining the pathological and clinical features of any case. Despite the fundamental importance of the underlying genetic change or changes, no classification of acute leukaemia has yet systematically incorporated the results of such analysis. It is already possible to recognise many subtypes of AML and ALL associated with specific genetic lesions. Even though knowledge is imperfect, enough information is available to provide the basis for a classification. The concepts of the FAB and MIC groups provide a framework The enlarged system could be described as the MIC-M classification, being based on morphology, immunophenotype, cytogenetic analysis, and molecular genetic analysis. The classification would incorporate the results of molecular genetic analysis but this would not be its sole basis since an apparently identical abnormality - for example $t(4 ; 11)$ (q21;q23) or $\mathrm{t}(9 ; 22)(\mathrm{q} 34 ; \mathrm{q} 11)$ with MLL-AF4 and BCRABL fusion, respectively - sometimes occurs in different diseases. Not all cases would require molecular genetic analysis, since some can be recognised by morphology alone, or by a combination of morphology and conventional cytogenetics. Nevertheless the nature of the genetic lesion would be one of the features defining a category. The proposed MIC-M classification would not be incompatible with a categorisation of cases of acute leukaemia as "MDS related" or "de novo type AML." It is likely that many cases of "de novo type AML" and some cases of MDS related AML would 
Table 2 Some proposed MIC-M categories of acute myeloid leukaemia ${ }^{9-23}$

\begin{tabular}{|c|c|c|c|}
\hline Usual karyotype & Usual FAB category & $\begin{array}{l}\text { Probable molecular } \\
\text { genetic mechanism of } \\
\text { leukaemogenesis }\end{array}$ & $\begin{array}{l}\text { Approximate } \\
\text { percentage of cases } \\
\text { of } A M L \text { and } \\
\text { references }\end{array}$ \\
\hline \multicolumn{4}{|c|}{ Common subtypes (constituting at least $1 \%$ of all cases of $A M L$ ) } \\
\hline $\mathrm{t}(8 ; 21)(\mathrm{q} 22 ; \mathrm{q} 22)$ & M2 & AML1-ETO & $9 \%{ }^{910}$ \\
\hline $\begin{array}{l}\mathrm{t}(15 ; 17)(\mathrm{q} 22 ; \mathrm{q} 11-12) \\
\text { inv }(16)(\mathrm{p} 13 \mathrm{q} 22) \text {, or }\end{array}$ & $\mathrm{M} 3, \mathrm{M} 3 \mathrm{~V}$ & PML-RAR $\alpha$ & $9 \%{ }^{9}$ \\
\hline $\begin{array}{l}\mathrm{t}(16 ; 16)(\mathrm{p} 13 ; \mathrm{q} 22) \\
\operatorname{inv}(3)(\mathrm{q} 21 \mathrm{q} 26) \text { or }\end{array}$ & M4Eo & CBF $\beta-M Y H 11$ & $3-6 \%{ }^{911}$ \\
\hline $\mathrm{t}(3 ; 3)(\mathrm{q} 21 ; \mathrm{q} 26)$ & Various, including $M 7$ & EVII dysregulation & $1-2 \%{ }^{9}$ \\
\hline Abnormality involving & & MLL gene & \\
\hline the MLL gene at 11q23: & M4 or M5 & rearranged & $4-10 \%$ \\
\hline $\mathrm{t}(1 ; 11)(\mathrm{p} 32 ; \mathrm{q} 23)$ & M5 & MLL-AF1p & 912 \\
\hline $\mathrm{t}(1 ; 11)(\mathrm{q} 21 ; \mathrm{q} 23)$ & M4 & MLL-AF1q & 12 \\
\hline $\mathrm{t}(4 ; 11)(\mathrm{q} 21 ; \mathrm{q} 23)$ & M5 & MLL-AF4 & 912 \\
\hline $\mathrm{t}(6 ; 11)(\mathrm{q} 27 ; \mathrm{q} 23)$ & M4 or M5 & MLL-AF6 & 912 \\
\hline $\mathrm{t}(9 ; 11)(\mathrm{p} 22 ; \mathrm{q} 23)$ & M5 & MLL-AF9 & 912 \\
\hline ins $(11 ; 9)(\mathrm{q} 23 ; \mathrm{p} 22 \mathrm{p} 23)$ & M5 & MLL-AF9 & \\
\hline $\mathrm{t}(10 ; 11)(\mathrm{p} 12 ; \mathrm{q} 23)$ & M5 & MLL-AF10 & 9 \\
\hline $\mathrm{t}(11 ; 16)(\mathrm{q} 23 ; \mathrm{p} 13)$ & $\mathrm{M} 2, \mathrm{M} 4, \mathrm{M} 5$, or MDS & MLL-CBP & 1314 \\
\hline $\mathrm{t}(11 ; 17)(\mathrm{q} 23 ; \mathrm{q} 21)$ & M5 & MLL-AF17 & 9 \\
\hline $\mathrm{t}(11 ; 19)(\mathrm{q} 23 ; \mathrm{p} 13.1)$ & M4 or M5 & MLL-ELL & 9 \\
\hline $\mathrm{t}(11 ; 19)(\mathrm{q} 23 ; \mathrm{p} 13.3)$ & MR or M5 & MLL-ENL & 9 \\
\hline $\mathrm{t}(\mathrm{X} ; 11)(\mathrm{q} 13 ; \mathrm{q} 23)$ & M4 or M5 & MLL-AFX & 9 \\
\hline $\begin{array}{l}\text { Normal, } 11 \mathrm{q}+\text {, or } \\
\text { trisomy } 11\end{array}$ & M1 or M2 & $\begin{array}{l}\text { Partial tandem } \\
\text { duplication of MLL }\end{array}$ & 15 \\
\hline \multicolumn{4}{|c|}{ Uncommon or rare subtypes (each constituting less than $1 \%$ of cases of $A M L$ ) } \\
\hline \multirow[t]{3}{*}{$\mathrm{t}(3 ; 21)(\mathrm{q} 26 ; \mathrm{q} 22)$} & Various & AML1-EAP & 9 \\
\hline & & AML1-MDS1 & 9 \\
\hline & & AML1-EVI1 & 9 \\
\hline $\mathrm{t}(3 ; 5)(\mathrm{q} 25.1 ; \mathrm{q} 34)$ & Various & NPM-MLF1 & 9 \\
\hline $\mathrm{t}(5 ; 17(\mathrm{q} 32 ; \mathrm{q} 21)$ & M3 & NPN-RARA & 16 \\
\hline $\mathrm{t}(6 ; 9)(\mathrm{p} 23 ; \mathrm{q} 34)$ & M2 Baso & DEK-CAN & ${ }^{9}$ \\
\hline $\mathrm{t}(7 ; 11)(\mathrm{p} 15 ; \mathrm{p} 15)$ & M2 & $\begin{array}{l}\text { NUP98-HOXA9 } \\
\text { fusion }\end{array}$ & 17 \\
\hline $\mathrm{t}(8 ; 16)(\mathrm{p} 11 ; \mathrm{p} 13)$ & M4 or M5 & $\mathrm{MOZ}-\mathrm{CBP}$ fusion & 18 \\
\hline $\mathrm{t}(9 ; 22)(\mathrm{q} 34 ; \mathrm{q} 11)$ & $\mathrm{M} 0, \mathrm{M} 1$, or M2 & BCR-ABL fusion & 9 \\
\hline $\operatorname{inv}(11)(\mathrm{p} 15 \mathrm{q} 22)$ & AML or MDS & $\begin{array}{l}\text { NUP98-DDX10 } \\
\text { fusion }\end{array}$ & 19 \\
\hline $\mathrm{t}(11 ; 17)(\mathrm{q} 23 ; \mathrm{q} 21)$ & M2-M3 & $\begin{array}{l}\text { PLZF-RAR } \alpha \text { fusion } \\
\text { and RAR } \alpha-P L Z F \\
\text { fusion }\end{array}$ & 20 \\
\hline $\mathrm{t}(12 ; 22)(\mathrm{p} 13 ; \mathrm{q} 11)$ & Various & MN1-TEL fusion & 21 \\
\hline $\mathrm{t}(16 ; 21)(\mathrm{p} 11 ; \mathrm{q} 22)$ & Various & FUS-ERG fusion & ${ }^{9}$ \\
\hline
\end{tabular}

fall into MIC-M categories. Other MDS related cases with multiple genetic lesions would not. Some proposed MIC-M categories of acute myeloid leukaemia are shown in table $2 .^{9-23}$ ALL could be similarly categorised.

Molecular techniques which would be applicable in the MIC-M classification include fluorescence in situ hybridisation techniques (FISH), Southern blotting, genomic polymerase chain reaction (PCR) and reverse transcriptase (RT) PCR.

Incorporating molecular genetic analysis into the description of specific types of acute leukaemia has three advantages: (1) cases with atypical cytogenetic findings or with failed cytogenetic analysis can be included in the appropriate category; (2) subtypes which lack a characteristic cytogenetic abnormality but nevertheless have a characteristic molecular genetic abnormality can be recognised; and (3) subtypes which have morphological and cytogenetic similarities but which differ at the molecular level can be distinguished. Although many cases of AML could be assigned to an MIC-M category without recourse to molecular genetic analysis it has been shown that the rate of detection of several good prognosis subtypes of AML is greatly increased by the routine application of such techniques. $^{24}{ }^{25}$ Because of the implications for prognosis and choice of treatment, the routine application of molecular techniques could therefore be justified.
Acute hypergranular promyelocytic leukaemia and its variant form (M3 and M3v AML) provide good examples of the need for an MIC-M classification. The majority of cases of M3/M3v AML show $\mathrm{t}(15 ; 17)(\mathrm{q} 22 ; \mathrm{q} 21)$. However, cytogenetic analysis sometimes fails. Results are sometimes normal, either because only erythroblasts have entered mitosis or because no microscopically detectable rearrangement is present. Sometimes an unrelated cytogenetic abnormality such as trisomy 8 is all that is detected. All such cases should be categorised as $\mathrm{M} 3 / \mathrm{M} 3 \mathrm{v}$ if PML-RARA fusion is demonstrated by molecular techniques. Simple and complex variant translocations should similarly be included in this category if PMLRARA fusion has occurred. The MIC-M classification would, however, exclude cases with a translocation which is indistinguishable from that of M3 AML by conventional cytogenetic analysis but which lack PML-RARA rearrangement and M3 morphology. The MIC-M classification would recognise AML with $\mathrm{t}(11 ; 17)(\mathrm{q} 23 ; \mathrm{q} 21)$ as an entity separate from $M 3 / t(15 ; 17){ }^{20}$ The molecular mechanism of leukaemogenesis differs in this subtype, being related to a PML-PLZF fusion rather than a PML-RARA fusion. Cytological features show subtle differences, being intermediate between those of M3 and those of M2 AML. A shorthand description of these two subtypes of acute leukaemia would thus be: M3/M3v AML/t(15;17)(q22;q21)/PMLRARA fusion, and

M2-M3 AML/ t(11;17)(q23;q21)/PMLPLZF fusion.

The important biological difference between these two subtypes of AML is shown by the worse prognosis of the latter subtype and its refractoriness to differentiating therapy with all-trans retinoic acid, a treatment which is particularly effective in the former subtype. This rare subtype of acute leukaemia also illustrates why a leukaemia classification cannot be based on cytogenetics alone, since $\mathrm{t}(11 ; 17)(\mathrm{q} 23 ; \mathrm{q} 21)$ can be associated not only with M2-M3 AML with PML-PLZF fusion but with a totally different subtype of AML, M5 AML with MLL-AF17 fusion. ${ }^{9}{ }^{12}$

Another illustration of the advantages of the proposed MIC-M classification is that ALL with TEL-AML1 fusion can be recognised as an entity, whether or not $\mathrm{t}(12 ; 21)(\mathrm{p} 12 ; \mathrm{q} 22)$ is detected. ${ }^{25}$ This translocation is usually cryptic since the banding pattern of the parts of the chromosomes involved in the translocation is identical. This is the commonest genetic abnormality in childhood B-lineage ALL but was largely unrecognised until cytogenetic analysis was supplemented by molecular genetic analysis. A shorthand description of this entity would be L1 or L2/early precursor or common ALL/t $(12 ; 21)(\mathrm{p} 12 ; \mathrm{q} 22)$ (cryptic)/ TEL-AML1 fusion.

Similarly, the MIC-M classification would recognise as an entity $\mathrm{T}$ lineage ALL with a deletion related to the TAL gene. ${ }^{9}$ By conventional cytogenetic analysis, chromosome 1 may appear normal since the deletion may be very small. There is dysregulation of the TAL gene 
as a result of a deletion which brings it into proximity to the upstream SIL gene. This subtype of leukaemia would be described as $\mathrm{L} 1 / \mathrm{L} 2 / \mathrm{T}$ lineage ALL/normal karyotype/TAL ${ }^{\mathrm{d}}$. Likewise the MIC-M classification would recognise as an entity a subtype of myeloid leukaemia which can be identified only by a combination of morphology, immunophenotyping, and molecular genetic analysis; this type of $\mathrm{AML}$, in which there is fusion of two genes located at $9 \mathrm{q} 34$, would be designated M0 AML/normal karyotype/SET-CAN fusion.

It will be noted that real entities, as described in the MIC-M classification, may overlap two or more categories in other classifications. For example, as mentioned above, an entity which would have an MIC-M description of M2 AML/t(8;21)(q22;q22)/AML1-ETO would fall into two different categories if a purely immunological classification ${ }^{4}$ were used. Similarly, if the FAB classification were applied, most cases would be categorised as M2 AML but some as M1 AML or even as RAEB-T (refractory anaemia with excess of blasts in transformation). If cases were classified by antecedent events, the great majority of cases would be classified as de novo AML but a minority would be designated treatment related AML following exposure to topoisomerase-II interactive drugs. This subtype of leukaemia appears to be a biological entity, even if it straddles two or more categories in other classifications. The MIC-M classification would recognise this.

It should be noted that it will not be possible to assign all cases of acute leukaemia to an MIC-M category since not only is our state of knowledge imperfect but some cases have multiple genetic lesions. The MIC-M classification, like the MIC classification, would be open ended with the possibility of new entities being added once their characteristics had been clearly defined.

\section{Conclusions}

Acute leukaemia can be classified in many ways. An ideal classification is one which recognises real entities with fundamental biological differences. Such a classification must incorporate molecular genetic analysis since it is likely that it is the genetic lesion which determines the clinicopathological features of a case. A MIC-M classification is proposed which incorporates morphology, cytochemistry, immunophenotype, cytogenetic analysis, and molecular genetic analysis. The genetic abnormality would be given priority in defining a subtype, although it would be interpreted only in the context of the morphological and immunophenotypic features. Once the characteristics of a subtype were recognised it would not be necessary to apply all diagnostic modes to all cases in order to assign them to the correct categories. Molecular genetic analysis is already considered in the choice of treatment. For example, some centres employ molecular techniques to detect cases of ALL with MLL-AF4, BCR-ABL, or E2A$\mathrm{PBX} 1$ fusion genes rather than using cytogenetic techniques to detect the corresponding $\mathrm{t}(4 ; 11)(\mathrm{q} 21 ; \mathrm{q} 23), \quad \mathrm{t}(9 ; 22)(\mathrm{q} 34 ; \mathrm{q} 11), \quad$ and $\mathrm{t}(1 ; 19)(\mathrm{q} 23 ; \mathrm{p} 13)$ rearrangements or, similarly, to detect the molecular equivalents of $\mathrm{t}(8 ; 21)(\mathrm{q} 22 ; \mathrm{q} 22), \mathrm{t}(15 ; 17)(\mathrm{q} 22 ; \mathrm{q} 11-12)$, and $\operatorname{inv}(16)(\mathrm{p} 13 \mathrm{q} 22) .{ }^{11}$ It is proposed that such information now be integrated into the classification for acute leukaemia.

I am grateful to Professor David Galton who has kindly read several drafts of this review and has discussed some difficult points with me.

1 Bennett JM, Catovsky D, Daniel MT, et al. Proposals for the classification of the acute leukaemias (FAB cooperative classification of the acute leukaemia

2 Froup). Br f Haematol 1976;33:451-8. First MIC Cooperative Study Group. Morphologic, immu-
nologic, and cytogenetic (MIC) working classification of acute lymphoblastic leukaemias. Cancer Genet Cytogenet 1986;23:189-97.

3 Second MIC Cooperative Study Group. Morphologic, immunologic and cytogenetic (MIC) working classification of the acute myeloid leukaemias. $\operatorname{Br} \mathcal{F}$ Haematol 1988;68: 487-94.

4 European Group for the Immunological Characterization of leukemia (EGIL), Bene MC, Castoldi G, Knapp W, et al. Proposals for the immunological classification of acute leukemias. Leukemia 1995;9:1783-6.

5 Hayhoe FG. The classification of acute leukaemia. Blood Rev 1988;2:186-93.

6 Head DR. Revised classification of acute myeloid leukemia. Leukemia 1996;10:1826-31.

7 Bennett JM, Catovsky D, Daniel M-T, et al. Criteria for the diagnosis of acute leukemia of megakaryocytic lineage (M7): a report of the French-American-British cooperative group. Ann Intern Med 1985;103:460-2.

8 Bennett JM, Catovsky D, Daniel MT, et al. Proposal for the recognition of minimally differentiated acute myeloid leukaemia (AML M0). Br f Haematol 1991;78:325-9.

9 Drexler HG, Borkhardt A, Janssen JWG. Detection of chromosomal translocations in leukemia-lymphoma cells by polymerase chain reaction. Leuk Lymphoma 1995;19: 359-80.

10 Andrieu V, Radford-Weiss I, Troussard X, et al.. Molecular detection of $\mathrm{t}(8 ; 21) / A M L 1-E T O$ in AML M1/M2: correlation with cytogenetics, morphology and immunophenotype. Brf Haematol 1996;92:853-65.

11 Langabeer SE, Walker H, Gale RE, et al. Frequency of CBF//MYH11 fusion transcripts in patients entered into the UK MRC AML trials. Br f Haematol 1997;96:736-9.

12 Rubnitz JE, Behm FG, Downing JR. 11q23 rearrangements in acute leukaemia. Leukemia 1996;10:74-82.

13 Rowley JD, Reshmi S, Sobulo O, et al. All patients with the $\mathrm{t}(11 ; 16)$ (q23;p13.3) that involves MLL and CBP have treatment-related hematologic disorders. Blood 1997;90: 535-41.

14 Taki T, Sako M, Tsuchida M, et al. The $\mathrm{t}(11 ; 16)$ (q23;p13) translocation in myelodysplastic syndrome fuses the MLL gene with the CBP gene. Blood 1997;89:3945-50.

15 Caligiuri MA, Strout MP, Gilliland DG. Molecular biology of acute myeloid leukemia. Semin Oncol 1997;24:32-44.

16 Redner RL, Rush EA, Faas S, et al. The $\mathrm{t}(5 ; 17)$ variant of acute promyelocytic leukemia expresses a nucleophosminacute promyelocytic leukemia expresses a nucleoph
retinoic acid receptor fusion. Blood 1996;87:882-6.

17 Huang S-Y, Tang J-L, Liang Y-J, et al. Clinical, haematological and molecular studies in patients with chromosome translocation $t(7 ; 11)$ : a study of four Chinese patients in translocation $\mathrm{t}(7 ; 11)$ : a study of four
Taiwan. Br 7 Haematol 1997;96:682-7.

18 Aguiar RCT, Chase A, Coultard S, et al. Molecular investigation of chromosome band 8p11 in two distinct leukaemia syndromes. Br F Haematol 1997:97(suppl 1):5.

19 Arai Y, Hosoda F, Kobayashi H, et al. The inv(11)(p15q22) chromosome translocation of de novo and therapy-related myeloid malignancies results in fusion of the nucleoporin gene NUP98 with the putative RNA helicase gene, DDX10. Blood 1997;90:3936-44.

20 Licht JD, Chomienne C, Goy A, et al. Clinical and molecular characterization of a rare syndrome of acute promyelocytic leukemia associated with translocation $(11 ; 17)$. Blood 1995;85:1083-94.

21 Wlodarska I, Mecucci C, Baens M, et al. ETV6 gene rearrangements in hematopoietic malignant disorders. rearrangements in hematopoietic

22 Evans P, Jack A, Short $M$, et al. A single tube nested RT-PCR for selecting the common myeloid specific chromosomal translocations. Leukemia 1995;9:1285-6.

23 Mrózek K, Heinonen K, de la Chapelle A, et al. Clinical significance of cytogenetics in acute myeloid leukemia. Semin Oncol 1997;24:17-31.

24 Langabeer SE, Walker H, Rogers JR, et al. on behalf of the MRC Adult Leukaemia Working Party. Incidence of AML1/ETO fusion transcripts in patients entered into the MRC AML trials. Br f Haematol 1997;99:925-8.

25 Grimwade D, Howe K, Davies L, et al. Establishing the presence of the $\mathrm{t}(15 ; 17)$ in suspected APL; cytogenetic, molecular and PML inunorescence assessment of tol 1996;93(suppl 2):221.

26 Romana SP, Poirel H, Leconiat $\mathrm{M}$, et al. High frequency of $\mathrm{t}(12 ; 21)$ in childhood B-lineage acute lymphoblastic leukemia. Blood 1995;86:4263-9. 